tortuosity in cases in which there is inequality of the radial pulses, slight tracheal tugging, dyspnoea, and in which the symptoms are stationary for a considerable period of time and the fluoroscope shows a projection to the left of the descending portion of the arch of the aorta that has expansile pulsation.

\title{
REFERENCES.
}

1. Sansom. Diseases of the Heart. London.

2 Levy-Dorne. Congress f. innere Medicin, Berlin, 1897, p. 316.

3. Gocht. Lehrbuch der Rïntgenuntersuchumg, Stuttgart, 1898, p. 199.

4. Dumstrey and Metzner. Fortschritte suf. dem Gehiete der Rintgenstrahen, vol, i.

5. Holaknecht. Wiener klin. Woch., 1900, No. 10.

6. Weinberger. Atlas der Radiographie der Brustorgane, Vienna, 1901.

7. Immelmann. Köntgen Atlas deg Normalen Menschlichen Kürpers, Berlin, 1900.

\section{THE OCCURRENCE OF THE BENCE-JONES ALBUMIN IN A PLEURITIC EFFUSION.}

\author{
By ISADOR H. CORIAT, M.D., \\ WORCESTER INSANE HOSPITAL.
}

TrF peculiar albumose-like body which has been named after BenceJones, who first gave it serious research, has during recent years demanded much attention. It is found in the urine of patients auffering from maliguant bone disease, in particular either multiple myeloma or sarcomatosis, and also in the blood and bone-marrow of these conditions. Formerly it was thought to occur in osteomalacia, but it is now recognized by more modern methods of examination that what had been previously designated as osteomalacia is in reality multiple myeloma. The uniting of these facts has made the urinary examination of the highest importance in the diagnosis of obscure bone disease, especially those in which there is an absence of metastasis and several bones become simultaneouisly the seat of the new-growth. An albumose resembling the Bence-Jones body has been described by $R$. Fleischer ${ }^{1}$ as occurring in normal bone-marrow, but further research along this line by the more modern methods of the separation of various albumoses seems to be necessary. The substance has also been encountered in the urine of animals the subjects of experimental pyrodin anæmia. To these findings I am now able to add to the reported series a case in which the Bence-Jones albumin could be demonstrated in large quantities in the pleuritic effusion of a patient suffering from multiple neuritis associated with extreme tenderness of the ribs, while it was absent from the urine. So far as I am able to discover this is a new observation, and one which I hope will cast some light on the muchdiscussed question of the origin of this substance. Although the 
pleuritic elfusiou was very slightly pnrnlent, yet in the literature there can be found only the vaguest references to the occurrence of "albumose" and "peptone" in pns and pathological pleuritic flnids. $\mathrm{My}_{\mathrm{y}}$ case is the first to occur in the wards of an insane hospital, and the patient was the subject of an extensive multiple neuritis associated with a peculiar mental condition, of which the prominent symptoms were a profound memory defect associated with extensive fabrications. The clinical history is given in detail in order that the reader may judge of the varied symptom-complex under which this body nay be demollstrated.

Polyneuritic delirium (Kersukow's disease); alcoholic excesses; multiple neuritis; extreme tenderness of the ribs; plenrisy with effusion; albumose in the pleuritic fluid; wine negative; no ancemia. 'The patient was an Englishman, aged forty-two years, of whose personal history but little is known, except that for several years he drank heavily aud was frequently intoxicated. He was admitted to the Worcester Insane Hospital on October 29, 1902, with a certificate stating that the onset of his trouble had been several weeks previously, that he was in poor bodily health, and in a state of complete mental confusion. On admission to the hospital he was inmediately placed in bed on account of his weak condition, as he was scarcely able to stand. There was a profound delirium with disorientation, prominent memory defect for both recent and remote impressions, aud extensive fabrications which he constantly utilized to fill up the gaps in his memory. The mental condition has remained unchanged since admission. He was occasionally noisy at night.

The physical examination showed the following:

A iniddle-aged, fairly well-developed but poorly nourished man; weight, 130 pounds. Tongue covered with a brownish coating. The pupils are equal and react promptly to light and accommodation. There is a tendency to nystagmus in the horizontal movements of the eyes. Knee-jerks slightly exaggerated on the right, the left about normal. The tongue protrudes in the median line and has a fine tremor. There is a tremor of the lips when the teeth are shown. The grasps are very weak, and the mnscnlar power of the extremities shows considerable weakness of the extensor muscles, the feet drooping as the patieut lies in bed. He is unable to stand withont snpport and complains of feeling dizzy. The examination of the chest shows a marked lack of expansion on the left side, with dulness in the region of the lower lobe, almost complete absence of breath sounds, and diminished vocal resonance. Pulse 100 and weak. Arteries every where thickened. Hands and feet cold. The nrine showed a trace of albumin, diminished indican, and a few hyaline casts. Stools daily and regular. Occasionally the evening temperature rose to $100^{\circ}$. He gradually grew weaker, with continued fever and increasing delirium. On November 14 th there was marked dyspnca, and examination of the lnngs showed complete dnlness in the lower part of the chest, with diminished vocal fremitus. The chest was aspirated and about 1500 c.c. of a clear, amber fluid withdrawn, which resnlted in considerable relief of the dyspnœa. On November 17 th the knee-jerks were found to be absent 
and the iuuscles showed considerable wastiug, although the electrical reactions were normal. The fever continued, occasioually reachiug $101^{\circ} \mathrm{F}$., and on December 1st there was a return of the dyspncea. The physical examination of the lungs showed the same condition as previously. The knee-jerks were still absent aud the atrophy of the leg muscles more marked, the circumference of the left leg being from $1 \mathrm{~cm}$. to $2 \mathrm{~cm}$. less thau on the right. There was some paiu and tellderness over the nerve trunks. The left pleural cavity was again aspirated ou February 10,1903, and about 400 c.c. of a clear fluid withdrawn. This was repeated on March $2 d$, aud 1800 c.c. of an amber serum aspirated. From the time of admission up to May, 1903, the patient lost twenty pounds in weight. The meutal and physical condition remained uuimproved. On May 26, 1903, 1050 c.c. of fluid was again aspirated from the left side of the chest, and it was this fiuid which I had the opportuuity of examiuing.

Analysis of the Pleuritic Fluid. Amount, 1050 c.c. ; color, greeuishyellow and semi-opaque; specific gravity, 1027 ; odor, none; reaction, neutral. The amount of sediment was small. On standing in a tall, cylindrical litre graduate for twelve hours it did not occupy more than $\frac{1}{2} \mathrm{~cm}$. The microscopic examination showed a fair number of nornal pus cells, the absence of cholesterin crystals, and a few blood cells (contamination from aspiration with the trocar).

Fibrin was absent. There was no spontaneous coagulation. On heatiug there was a fairly firm coagulation of serum albumin and globulin. On adding 10 per cent. acetic acid in the cold there resulted a fair precipitate of nucleoproteid. A portion of the fluid was made slightly acid with acetic acid and the other proteids removed by boiling. The filtrate was slightly cloudy, which cloudiness could not be removed by continued filtration. Tests for serum albumin and globulin and nucleoalbumin showed all to be entirely absent.

On the addition of a few drops of nitric acid to the filtered fluid there resulted a heavy white precipitate, not soluble in excess of the acid, but which completely cleared up on heating and reappeared on cooling with the simultaneous appearance of the xanthoproteic reactiou. The same reaction was obtained with sulphosalicylic acid. 'The amount of this albumose-like body was large and reached 4 per cent. in the Esbach albuminometer. As this substance was undoubtedly an albumose, its further investigation was decided upon.

Repeated examiuations of the urine showed it to be free from both albumin and albumose. Further examiuation of the patient revealed extreme tenderness on pressure over the sixth to the tenth ribs on the left side, with some crepitation under the skin, but without any herpetic eruptiou. No nodules or swellings were felt along the liue of the ribs, and the long bones of the legs and arms were free from paiu, both to pressure and percussion. A few days later this tenderness disappeared. There was no evidence of ansmia, and the blood exaniuation showed: Hæmoglobin, 100 per cent.; erythrocytes, 4,800,000; lencocytes, 7640 .

Reactions of the Native Fluid. A portion of the fluid was diluterl with water, and 10 per cent. acetic acid added to a slightly acid reaction. There resulted a moderate precipitate of nucleoproteid. The fluid was then heated upon the water-bath until the native albumin was coagulated and the rather heavy coagulation filtered off by aid of au exhaust 
filter. The slightly cloudy filtrate was found to be free from serum albumin and globulin and nucleoproteid. This native fluid responded to the following reactions:

On heating there resulted a slight milkiness at first, but the fluid rapidly became opaque. As the boiling point was reached white fiakes appeared in a clear liquid, which rapidly settled to the bottom of the tube as a fine, flocculent precipitate, which did not increase on cooling. Heller's test was positive, a broad white ring.

On the addition of a few drops of nitric acid a heavy white precipitate formed in the cold, which did not dissolvc in excess of the acid, but almost completely disappeared on boiling (the fluid at the same time turning yellow), and reappeared on cooling as a granular, yellowish precipitate. This turned to orange on the addition of a strong alkali (xanthoproteic reaction).

Hydrochloric acid produced the same result, with the exception that on heating the precipitate at first grew more dense and then disappeared as the boiling point was reached. Sulpluric acid produced a similar reaction. With phosphoric acid there was a white precipitate in the cold, which did not disappear on heating. Sulphosalicylic acid produced a heavy white precipitate in the cold, which disappeared on heating and reappeared on cooling. It was noted that the reaction was more marked in this case than with any other acid reagent.

On the addition of acetic acid even in excess the solution remained clear, both in the cold and on heating. Tannic acid caused a heavy, yellowish-brown precipitate, which grew more dense on heating. Both picric acid and Esbach's reagent caused a heavy yellow precipitate, which did not disappcar on warming.

The addition of phosphotungstic acid in the presence of a few drops of hydrochloric acid caused a heavy, white precipitate, which curdled on heating, but did not disappear. Acetic acid and potassium ferrocyanide produced a heavy precipitate, which grew more dense on heating.

On the addition of Lugol's solution no precipitate was obtained. Alcohol precipitates the substance as a flocculent mass readily soluble in very dilute ammonia or sodium-carbonate solution.

The resulting solution gives the albumose reactions with sulphosalicylic and nitric acids. Millon's reaction, intense brick-red; Adamkiewicz reaction, deep purplish-red; xanthoproteic reaction, strong; Molisch's reaction, the sulphuric acid turns green almost immediately, and on standing a short while a purplish-red ring forms at the junction of the acid and the fluid; biuret reaction, intense purplish-red reaction with the native fluid.

To another portion was added phosphotungstic acid and a few drops of $\mathrm{HCl}$, the resulting heavy, white precipitate washed with absolute alcohol, dissolved in weak sodium-hydrate solution, and heated until it became colorless. On the addition of a few drops of a weak coppersulphate solution to this fluid a purplish-red biuret reaction resulted. The solution remained clear on the addition of an excess of a saturated sodium-chloride solution. On heating there was a very slight turbidity, but no precipitate resulted. This turbidity could not be removed by filtration. In the presence of a few drops of 10 per cent. acetic acid, however, a saturated salt solution caused a heavy, white precipitate, which did not disappear or grow less on boiling. Saturation with sodium 
chloride in substance or with rock salt did not cause a precipitate at room temperature until the point of saturation was reached. This was hastened by warıning. Saturation with magnesium sulphate in the presence of acetic acid caused a complete precipitation of the substance.

The addition of twice the amount of a saturated solution of ammonium sulphate to the neutral fluid caused a complete precipitation of the body. The substance was not dialyzable and could not be precipitated by dialysis, even from salt-containing solutions.

After coagulation by heat the coagulum went into clear solution on warming with distilled water to which was added a little sodium carbonate or acetic acid. From this solution it could be precipitated by alcohol. The substance could not be precipitated from its acid solutions on neutralizing with ammonia or even when it was added in excess. The neutral solution remained clear, even on largely diluting with water. $\mathrm{On}$ passing $\mathrm{CO}$, through the neutral solution no precipitate resulted. Gravimetrically, the amount of the albumose was 4.36 per cent. The sulphur test was marked: a dark brown color which rapidly became black, and, finally, a black precipitate.

Coagulation Temperature. There was a slight beginning opalescence at $43.5^{\circ} \mathrm{C}$., which became more marked at $50^{\circ} \mathrm{C}$. The solution began to be turbid at $65^{\circ} \mathrm{C}$. aud opaque at $67^{\circ} \mathrm{C}$, so that the bulb of the thermometer could scarcely be seen. Flocculi began to separate at $69^{\circ} \mathrm{C}$, and at $69.5^{\circ} \mathrm{C}$. these flocculi rapidly settled to the bottom of the tube and assumed a granular appearance.

Crystallization. On slow precipitation by gradual heating the substance became grauular in appearance, and under the microscope conld be found a large number of gleaming white oval and round sphero. liths resembling leucin. In many of these could be seen concentric and radiating lines. These crystals were easily soluble in dilute hydrochloric and acetic acid and in sodium carbonate. No crystals could be obtained when the native solution was allowed to stand for several days or to slowly evaporate. A portion was precipitated with a saturated solution of ammonium sulphate and evaporated over calcium chloride, but crystallizatiou failed to take place.

Reactions of the Isolated Substance. To another portion of the fluid there was added twice its volume of a saturated solution of ammonium sulphate. The resulting heavy precipitate was filtered off, dissolved in hot water, and dialyzed for some time. Even on prolonged dialysis, however, it was found impossible to get rid of all the salt. The most delicate tests failed to show that the substance was dialyzable, and neither was it precipitated as the amount of salt grew less. The solution had a slight opalescence and was neutral in reaction.

It responded to the same color and precipitation tests as the native substance and also crystallized on slow heating, the erystals again resembling leucin. The reaction to various salts both in solution and in substance was likewise identical, and the coagulation point was at the same temperature. Evidently the trace of ammonium sulphate that was present and could not be removed by dialysis did not influence the various reactions, crystallizations, or coagulation point.

The following reactions, however, may be especially noted:

No precipitate occurred either on largely diluting with water or on the passage of $\mathrm{CO}_{2}$ through the liquid. On adding Lugol's solution, 
no precipitute. On addling an equal quantity of a saturated sodiunchloride solution there is no precipitate in the cold and only a slight opalescence on heating, which cannot be removed by filtration. If the same process be repeated with the addition of a few drops of acetic acid there results a heavy, flocculent precipitate in the cold, which grows more densc on heating. Saturation with sodium chloride in sulbstance or with rock salt causes a partial precipitation, which becomes complete on the addition of a few drops of acetic acirl. If coagulated by heat the coagulum dissolves readily, forming a clear solution on the addition of a few drops of acetic acirl or of a saturated solution of sodium carbonate. It can be precipitater from either of these solutions by neutralization with sodium carbonate (if acid) or with acetic acid (if alkaline), as the case unay be.

Elementwry Analysis. For elementary analysis and digestive experinents the albumose was precipitated with alcohol, the resulting precipitate washed several times with 95 per cent. alcohol, then absolute alcohol and ether, and clried over calcium chloride. The substance purified in this manner was almost pure white and responcled to the following reactions when dissolved in dilute ammonia, in which it was readily soluble: Biuret reaction, rose-red; Millon's reaction, intense vermillion-red; xanthoproteic reaction, marked; Moliscll's reaction, purplc at junction, the acid turning green; Arlankiewicz reaction, marked purplish-red; sulplur reaction, morlerate; nitric acid, white precipitate, which completely disappears on heating and reappears on cooling; sulphosalicylic acid, same as with nitric. With the pure dried substance Liebernian's reaction gave a dcep lilac color. The amount of nitrogen was 15.4 per cent. Both phosphorns and the xanthine bases were alosent, but there was a trace of iron. Sulpilur was present.

On warming a portion of the substance for an hour with dilute hydrochloric acid there was obtained a reducing body which gave marked reactions with Fehling's and Nylander's solutions. With phenylhyilrazin and sodium acetate there was obtained an osazone which crystallized in long and rather broad, yellow needles, but in too small an amount to determine their melting point. The hydrochloric acid phloroglucin test was negative.

Behavior on Digestion. (On digestion with trypsin in a slightly alkaline medium at $40^{\circ} \mathrm{C}$. for forty-eight hours the substance went into complete solution. To neutralization precipitate was obtained with acetic acid. The test for protein chromogen with bromine-water was well marked, and there was a large yield of tyrosin and but little leucin. The leucin and tyrosin were identified by their crystalline form and the latter in addition by its intense Millon reaction. I regret that iny ulaterial was not sufficient for peptic digestion.

From the above reactions we can conclude that the pleuritic fluid contained the so-called albumose of Bence-Jones, which was formerly thought to occur only in malignant bone disease, but which later investigations have shown to be present in other conditions.

There have been reported cases of albumosuria associated with various neuritic disorders or with vague symptoms referable to the nervous system, and some of these at least seem to have been free from any bone or marrow disease. 
Sznator's case", in addition to a multiple sarcomatosis, had central lypoglossus and trigeminal paralysis, with great weakness and sensitiveness of the left peroneal and tibial nerves. The tongue was especially involved. The autopsy showed multiple myelogenous round-celled sarcoma of the ribs, double-sided fibrinous pleurisy, and chronic parenchymatous nephritis with amyloid degeneration. The brain showed no abnormality, and the medulla exhibited only an irregular distribution of the nuclei. In the urine, which was examinel by Rosin, ${ }^{3}$ large quantities of albumose could be demonstrated.

In Wright's case there was numbness of the feet, double vision, and strabismus. Hamburger's first case ${ }^{5}$ had frequent attacks of facial neuralgia. Boston's case e $^{6}$ suffered from gastrointestiual catarrh and peculiar nervous phenomena, attacks of obstinate constipation, radiating pains, vomiting, œedema, frequent attacks of urticaria, various paræsthesias, Ioss in weight, and marked anæmia. It is merely mentioned that the Bence-Jones body was present in the nrine and that its elimination was intermittent in character. No chemical details are given. Anders and Boston ${ }^{7}$ later report three cases in which the BenceJones albumose was found in the urine. Saturation with sodium chloride in neutral solutions caused a precipitate in but a portion of the substance, thus differentiating it from protoalbumose and heteroalbumose. The first case had cranial and facial neuralgia, tlie second suffered from various paresthesias and neuralgic paius in the lower limbs, while in the third case there was paralysis of the left side of the face. The authors contend that the body is more or less closely allied to peptone, globin, histon, and the digestive albumoses.

Since Simon collected the literature in 1902 there have beeu reported additional cases of Bence-Jones albumosuria associated with symptoms referable to the osseous system or to the blood. One of these (Jochmann and Schumm) is a furtlier report of the urine and post-mortem findings of a case already published. In Simon's case ${ }^{8}$ there was pain along the course of the eighth and ninth ribs, with extreme tenderness, and followed shortly afterward by a tumor mass, the size of a lima bean, near the sternal end of the eighth rib. There was marked anemia and great loss of weight. For three months before death there existed extreme pain of the left thigh, and five days before exitus spontaneous fracture of the left femur occurred. Deatb ensued a year after the onset of the first symptoms, but the partial antopsy that was allowed revealed no abuormality of the ribs. The diagnosis of multiple myeloma was made at the beginning of the disease on the basis of the urinary findings. There was polyuria, low specific gravity, acid reaction, and the sediment was free from casts. Heated to $55^{\circ} \mathrm{C}$. the urine yielded a heavy, white precipitate, which became a little clearer on boiling, to grow more turbid on cooling, and which again became clear 
on the addition of a few drops of acetic acid. Nitric acid yielded a precipitate which completely dissolved on boiling and reappeared ou cooling. The urine gave a strong biuret reaction. By Esbach's albuminometer the amount of proteid was 0.27 per cent. The author undertook an elaborate chemical study of this substance and concluded that it was closely related to the globulins, if, indeed, it is not a globulin itself. The body showed many points of resemblance with Nöel-Paton's crystalline globulin and witl Marcus' water-soluble globulin. He argues strongly against the purely albumose nature of the substance.

In Gutternik's and de Graff's case ${ }^{9}$ the albumin could be crystallized, and the authors refer to it as a crystalline urinary albumose. This, including Nöel-Paton's and my own, makes three cases in which the substance could be obtained in crystalline form.

Vickery's case ${ }^{10}$ was one of albumosuria occurring in the course of a pernicious anæmia without any symptoms or abnormalities referable to the bones. The urine was examined by Wood. By the heat test there formed an abundant precipitate which dissolved on boiling aud reappeared on cooling. No attempt was made to further identify the nature of this albumose-like body.

Jochmann and Schumm" report the case of a woman, aged thirtyseven years, which, in a preliminary communication, was called osteomalacia, ${ }^{12}$ but later, after an elaborate study, the diagnosis was changed to multiple myeloma. During life the case was submitted to a careful $\mathrm{X}$-ray examination. The Bence-Jones albumose was present in the urine, and Schumm gives an extensive chemical study of the body, arriving at the conclusion that it is not a true albumose, but stands midway between albumose aud albumin. He was able to demonstrate the presence of an albumose-like body in the blood, which resembled deuteroalbumose and did not give the histon reactions. Barr ${ }^{13}$ reports a urine that contained a proteid which coagulated at $60^{\circ} \mathrm{C}$. and could be precipitated by mineral acids, but was soluble in excess. It could be precipitated by ammonium sulphate, but not by magnesium or sodium sulphate. The amount of proteid varied from 1.2 per cent. to 2.4 per cent. The reactions given, however, do not prove the identity of this substance with the Bence-Jones albumin.

In Milroy's case ${ }^{14}$ there was a knotty swelling under one of the ribs which appeared like a new-growth. The urine, wlien made weakly acid with acetic acid, gave a precipitate by warming at $52^{\circ} \mathrm{C}$., which thickened to a coagulum and dissolved largely at $95^{\circ} \mathrm{C}$. It reappeared again on cooling. The amount of this proteid was 0.54 per cent. The urine gave the biuret, Millon's xanthoproteid, and sulphur reactions, but phosphorus was absent. Saturation with sodium chloride or with magnesium sulphate gave a very slight precipitate. Nitric acid 
gave a precipitate in the cold which dissolved on warming aud reappeared on cooling. By repeated precipitation with ammonium sulphate, the behavior of the substance on warming was not changed. If the urine was warmed rapidly to $100^{\circ} \mathrm{C}$. the substance did not appear on cooling. When the urine was saturated with sodium chloride and then heated the entire mass coagulated. It was impossible to crystallize the proteid. The substance as a whole appeared to resemble a deuteroalbumose, but behaved differently on warming.

In Simon's case of læukemia ${ }^{15}$ with atypical blood findings (absence of eosinophilic leucocytes) the Bence-Jones albumin could not be demonstrated in the urine, even on repeated examinations.

In addition to the above, in the urine of a case of puerperal delirium associated with an acute parenchymatous nephritis with occasional hemorrhagic exacerbations, and having a freezing point varying from $0.15^{\circ} \mathrm{C}$. to $1.6^{\circ} \mathrm{C}$., a high percentage of albumin, many casts, and a low chloride and urea elimination, I found large amounts of an albumose which gave the following reactions: Nitric acid, heavy, white precipitate in the cold, disappearing on heating and reappearing on cooling; sulphosalicylic acid, the same as with nitric acid, but more marked; biuret reaction, rose-red; sulphur test, marked; Molisch's reaction, marked; xanthoproteic reaction, strong; Millon's reaction, marked.

The addition of acetic acid causes no precipitate, either in the cold or on heating. With alcohol there arises a white precipitate which is easily dissolved in weak sodium carbonate, and the resulting solution gives the biuret reaction. My investigations on this case are not suffciently mature to warrant further detail.

The proteid substance found in the urine of the various cases cited was of an albumose nature, yet the finer chemical details differ somewhat. They were all associated with some profound metabolic disturbance, manifested clinically by either abnormal blood states, new-growths in the bones, or by various trophic or neuritic disorders. The reaction to mineral acids (especially nitric) seems to have been identical in all the cases. The slight variations occur in their physical states or in their composition on elementary analysis, but even the latter shows a remarkable resemblance, as will be seen from the following analyses of various observers :

Elementary Composition.

\begin{tabular}{|c|c|c|c|c|c|c|}
\hline \multicolumn{3}{|c|}{ Observer. } & N. & S. & P. & Fe. \\
\hline Bence-Jones & & . & 15.03 & Present. & Present. & .......... \\
\hline Kübne. & & . & . 16.55 & $" 6$ & ............... & ........... \\
\hline Nöel-Paton. & & . & . 16.06 & “ & Absent. & $\ldots$ \\
\hline Neumeister. & & - & . 15.55 & $" 4$ & “ & Trace. \\
\hline Simon. & & & $15.12-15.26$ & “ & .6 & $\ldots$ \\
\hline Coriat . & . & . & . 15.4 & $" 4$ & "6 & Trace. \\
\hline
\end{tabular}


The presence of the carbohydrate group is a prominent characteristic and is probably related to the hexoses, as it failed to give the reaction for pentoses with the phloroglucin-hydrochloric acid test. Pick, ${ }^{16}$ moreover, speaks of his fraction III. as containing a carbohydrate molecule and calls it a glycoalbumose, yet this group was present in his other secondary albumoses, although in a smaller amount. This fraction resembles my substance by its positive Molisch test, yet, on the other hand, differs from it in various precipitation and color reactions.

The Beuce-Jones body is also to be differentiated from various other proteids and albumoses, and the essential points may be stated as follows :

Histon is an albumose-like body found by Kossel in the red blood corpuscles of geese and also in febrile and leukæmic urine. It does not exist as such in the cells, but in combination with another body, presumably nuclcin. It contains 16.7 per cent. to 17.93 per cent. nitrogen, according to various observers. When treated with alcohol it becomes insoluble in sodium carbonate or dilute acids, it is precipitated by $\mathrm{CO}_{\text {, }}$ from neutral solutions and by ammonia from acid solutions, and is insoluble in excess of the reagent.

Heteroalbumose is precipitated by saturation with sodium chloride in neutral solutions, yields but little tyrosin on tryptic digestion, and contains 17.98 per cent. nitrogen. It is also precipitated on dialysis and does not contain a carbolydrate group in its molecule.

Protoalbumose is dialyzable to some extent, but is not precipitated on dialysis. It is non-crystalline and gives only a faint Adamkiewicz reaction, does not contain a reducing body, and is only partially precipitated by sodium chloride from its neutral solutions.

Serum globulin coagulates at $75^{\circ} \mathrm{C}$., is precipitated by diluting its salt-coutaining solutions with water, on dialysis after precipitation with various salts, by passing a stream of $\mathrm{CO}_{2}$ through its solutious, by half saturation with ammonium sulphate, or by complete saturation with sodium chloride. According to Mörner, ${ }^{17}$ it yields a reducing body on boiling with dilute acids.

With the ordinary albumins it has nothing in common. Peptone is uot precipitated by nitric acid or on saturation with ammonium sulphate.

Deuteroalbumose is an anticompound, and does not yield any amidoacids on tryptic digestion. It is precipitated by sodium chloride ouly on the addition of acetic acid, and does not give the nitric-acid reaction except in the presence of an excess of salt, and is dialyzable to some extent.

'The substance in my case gave all the ordinary albumose reactions, but unlike the albumoses it could be crystallized, and yet resembled the colloids in not being dialyzable, while protoalbumose and hetero- 
albumose are dialyzable to some extent. It seems to have existed in the Huid in a peculiar physical condition, as in Nöel-Paton's crystalline globulin, or in Cramer's three cases of emulsion albuminuria. ${ }^{18}$ Even on coagulation by both heat and alcohol it was capable of being easily dissolved by very dilute acids or alkalies and forming a clear solution, while histon is insoluble unsler the same conditions. Furthermore, unlike histon, it could not be precipitated by ammonia from its acid solutions. The Molisch reaction was positive, and the carbohydrate gronp present seemed to be related to the hexoses, while both protoalburuose aud heteroalbumose have no carbohydrate group in their molecule. It also differs from protoalbumose and heteroalbumose in being precipitable by saturated solutions of sorlium chloride only in the presence of acetic acid. The coagulatiou temperature was a definite one. Both phosphorus and the xanthin bases were absent, proving that the sulstance had no relation to the nuclein group. That it is a hemibody is showl by the large yield of tyrosin on tryptic digestion, while deuteroalbumose, the substance which the Bence-Jones albumin most resembles, is an antibody and does not yield the amido-acids when digested with trypsin. The behavior on boiling has been noted differently by various observers; witl some, the substance almost completely dissolved; in Nöel-Paton's case there was complete coagulation, while in Nimon's aud my own case there was no evidence of clearing, even when the boiling point was long sustained, but it is noteworthy that in loth cases the coaguluin was capable of easy solution.

The exact nature aud origin of the Bence-Jones sulstance has been the subiect of much contention. Simon believes that the body is closely related to the globulins; Huppert looks upon it as a heteroalbumose; while Kühne aud Chittenden found that on elementary analysis the body resembled heteroglobulose, and they suggest that it may arise from serum globulin. Magnus-Levy, on the other hand, did not believe that it belongerl to the globulins, on account of its behavior to magnesium sulphate.

There is 110 reason to believe that the snbstance is formed in the kidneys, but it is eliminated by these orgaus when abnormally present in the blood; yet here again direct proof is wanting as to the origin of the substance in that medium. Schumm was able to demonstrate in the blood of his case a body which resembled a deuteroalbumose. Followiug the introduction of the isolated body into the blood of auimals it rapidly appears in the uriue. The presence of an albumose-like substance in normal bone-marrow proves nothing, but it is interesting to note that both Wood aud Ellinger have found, in the affected portion of the marrow in malignaut bone disease, a proteid which gave all the albumose reactions. That the substance arises as the result of peptic or tryptic action upon ingested albumius, and thell passes into the 
blood stream, where, as a foreign substance, it is eliminated by the kidneys, is not to be thought of, because, as has been previously shown, the Bence-Jones albumin possesses nothing in common with the ordinary digestive albumoses. Simon claims that it is probably derived from the common albumins of the blood, in all probability the serum globulin, through the enzymotic action of the plasma cells of the bone-marrow, iu cases of myeloma, and from theuce passes into the urine. This, in the light of my own case, is at least very suggestive if not convincing. Up to this time, however, no case had been reported where the BenceJones albumin could be demonstrated in a pleuritic effusion, its occurrence being confined to the urine, blood, and bone-marrow. As a small amouut of pus cells were contained in the pleuritic fluid of my case, it must necessarily have been of inflammatory and probably also of bacterial origin, as shown by the clinical course of the disease. If we look upon the pleuritic effusion as being in reality an exudate from the blood, the origin of this substauce is probably from the same source, and can be referred to the action of enzymes contained either in the leucocytes or ill the micro-organisms upon either the serum albumin or serum globulin. The process is really a digestive one upon the ordinary albumils of the exudate, which have the same composition and ratio as the proteids of the blood, but which, as the result of this digestive action, have in part been changed to an albumose having all the characteristics of the Bence-Jones body, and existing in the fluid in an unusual physical state. But whether this action is principally upon the serum albumin or serum globulin, or both, cannot be definitely decided at present. In confirmation of the above, Fermi and Pampersi ${ }^{19}$ have shown that bacteria contain a proteolytic enzyme whose action upon proteids resembles that of trypsin. According to Austin," the prolonged action of micro-organisms ou nucleins, fibrin, and probably on other proteids, produces protoalbumoses and heteroalbumoses and secondary albumoses, $\mathrm{A}, \mathrm{B}$, and $\mathrm{C}$, according to Pick's scheme, but no peptone. These albumoses simulate those produced by trypsin.

In the light of this recent work it is easily conceivable how an albumose having all the peculiar characteristics of the Bence-Jones body could arise in this manuer from the native blood proteids as they werc exuded into a pathological pleuritic fluid. The medullary theory of the origin of the substance cannot be sustained, because there is not sufficient bone-marrow, even if all were involved, to account for the large amounts of albumose present in the various cases. In my case, at least, the rib tenderness was not sufficiently prominent to be suggestive of malignant bone disease.

In conclusion, it may be stated that the substance in my case was pre-eminently of an albumose nature, although probably not a true albumose, and haviug all the characteristics of the Bence-Jones albumin, 
but existing in the pleuritic fluid in an unusual physical state. It evidently was not absorbed and did not pass into the blood stream, as not even a trace of the substance could be detected in the urine. Furthermore, it seems to be a derivative of the digestive action of either the leucocytes or the bacteria upon the proteids in the effusion which are derived directly from the blood. Its origin can probably be traced to serum globulin rather than to serum albumin, as it possesses many features in common, both in reaction to various reagents and its composition on elementary analysis to Marcus" water-soluble globulin. The nitrogen content is about the same in both; neither are precipitated by dialysis or on the passage of $\mathrm{CO}_{2}$ through their solutions, and both give the sulphur, biuret, xanthoproteic, Adamkiewicz, and Molisch reactions.

\section{BIBLIOGRAPHY.}

1. R. Fleischer. Ueber das Vorkommen des sogenannten Bence.Jones'schen Eiwisskirper's Im normalen Knocbenmark. Virchow's Archiv, 1880, Bd. 1xxx.

2. H. Senator. Aesthenische Läbmung. Albumosurie und multiple Myelome. Berl. klin. Wocb., 1899 , No. 8.

3. H. Rosin. Ueber einen eigenartigen Eiseiss korper im Harn. Berliner klinik, 1897, No. 48.

4. J. H Wright. Transactions of the Association of American Physicians, 1900 .

5. Johns Hopkins Hospital Bulletin, $190 \mathrm{i}$.

6. L. Napoleon Boston. Beuce-Jones Alhumosuria, with Peculiar Nervous Phenomena. The American Journat, of the Medical Sciences, April, 1903.

7. J. M. Anders and L. Napoleon Boston. Bence-Jones Albumosuria, with a Report of Three Cases. Lancet, January 10, 1903.

8. Charles E. Simon. Observations on the Nature of the Beuce-Jones Albumin. TH AMerican Jotpral of the Medical Sciences, June, 1903.

9. A. Gutternik and C. J. de Graff. Ueber der Darstellungeiner krystalliniscben Harnalhumose. Zeit. f. physiol. Chemie, 1902, Bd. xxxiv.

10. H. F. Vickery. A Case of Albumosuria of the Pernicious Anæmia Type. Philadelphia Medical Journal, August 2, 1902.

11. G. Jochmann and O. Schumm. Zeit. f. klin. Med., Bd. xlvi., H. 5 u. 6.

12. Typiscbe Albumosurie bei Osteomalacie. M inch. med. Woch., 1901, p. 1340.

13. J. Barr. A Case of Myelopathic Albumosuria. Liverpool Medico.Chirurgical Journal, 1901.

14. J. A. Milroy. A Contrihution to the Knowledge of a Rare Form of Albumose Oreurring in the Urine. Journal of Pathology and Bacteriology, vol. vii. p. 95.

15. C. Simon. A Case of Myelogenous Leukæmia, with Several Lnusual Features. Tuk American Journal of the Medical Sciences, June, 1903.

16. Zur Kenntnis der peptischen Spaltungs producte des Fibrins. Beitr. z. chem. Physiolog. o. Pathologie, Bd. ii., S. 481.

17. Centralblatt f. Physiologie, 1893, No. 20.

18. Münch. med. Woch., January 21, 1902.

19. Il Policlinico, 1897 , No. 8.

20. A. E. Austin. The Products of Prolonged Bacterial Action on Proleins. Journal of Medical Research, vol. ix., No. 1. 